\title{
Creation of the united digital model of energy engineering complex
}

\author{
Alexey Dmitriev ${ }^{1, *}$, and Vyacheslav Gerasimov ${ }^{1}$ \\ ${ }^{1}$ Tyumen Industrial University, Volodarskogo Street, 38, 625000, Tyumen, Russia
}

\begin{abstract}
In the framework of the priority direction of the transformation of the Russian Federation domestic economy to digital format, the field of designing can become a key platform for the start of processes of digital transformation. The decisions laid down at this stage became the foundation for new objects. Not only the reliability and safety of the object operating, but also its modernity, competitiveness, economy, energy efficiency, and the ability to integrate into a developing digital community - all of it depends on the organization of the next steps in the construction and commissioning of the object, and also depends on the quality of a project engineering and quality of decisions made at this stage.
\end{abstract}

\section{Introduction}

As a rule, each functional unit of an organization is responsible for solving the tasks within its competence: the department of engineering is responsible for issuing project and detailed documentation, the department of construction is for building and commissioning the objects, the maintenance service is for organizing the failure-free state and safety of the object operating.

Each unit has its own tasks, plans for their implementation, in connection with which the following situations are possible:

- unnecessary time and resources to perform the same task by employees of different departments;

- omission from the zone of attention of tasks where the area of responsibility is blurred;

- unavailability of information that is in the area of responsibility of other units;

- the issuing of documentation, which at later stages is not viable and not claimed.

Overall, such a frequently occurring conservative approach may not affect the financial condition of individual units (enterprises, organizations), because overall, all the assigned tasks are carried out, but within the economy of the whole country it significantly restrains the growth of its productivity.

The possible solution to this problem is the creation of a united digital space, a digital model for each project, in which the necessary and relevant information will be present throughout the project life cycle, to which all interested departments will have access.

* Corresponding author: alextmn86@mail.ru 


\section{The digital model of energy engineering complex}

At this stage, the model is considered in the context of electrical discipline, but can be applied to all other disciplines, linking all sections and areas of designing. The structure of the proposed digital model of the project is pictured in Fig.1.

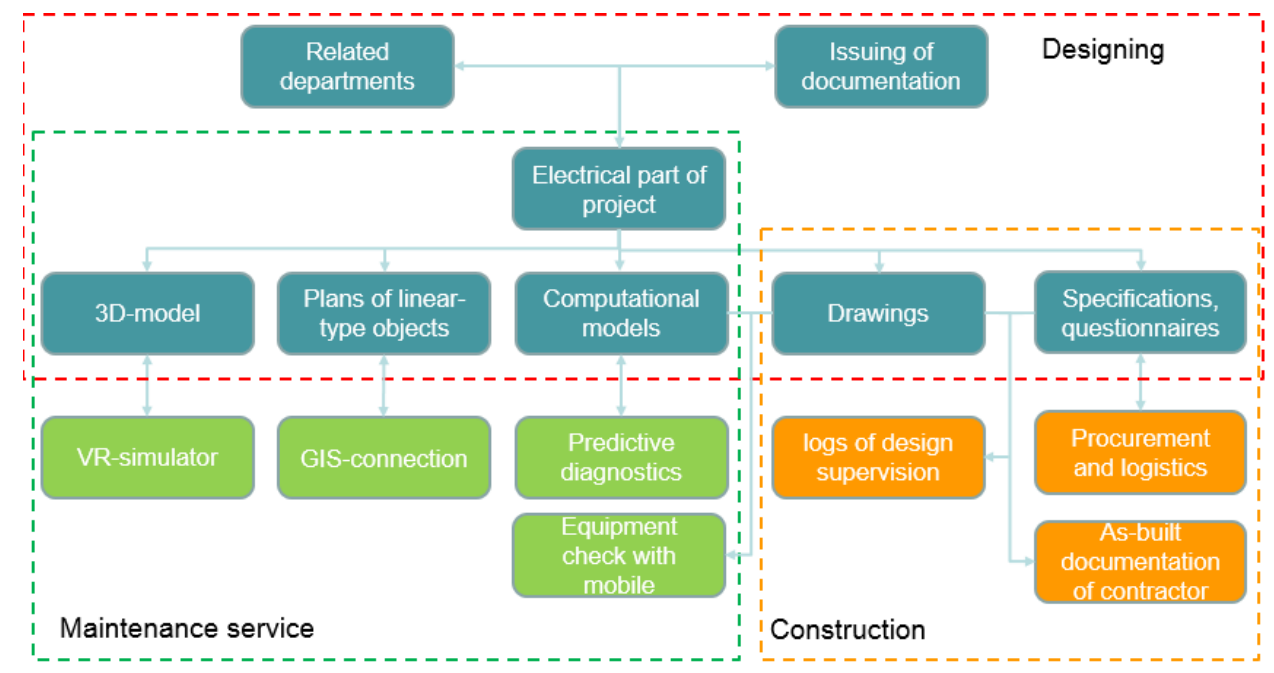

Fig. 1. The structure scheme of the proposed digital model of the project.

The storage of all information is organized in the network data warehouse by each unit in its area of responsibility. Filling of the network data warehouse happens at all stages of the project life cycle starting from the moment of pre-project solutions and finishing by decommissioning. During the implementation of this approach, it is expected to optimize the process of issuing documentation and its quantity, systematize workflows, and reduce the time to perform certain routine operations.

The key element, which allows not only to optimize the time spent on the release of the project, but also to reduce the number of collisions that occur between engineering communications of related departments, is the development of a 3D model. The ability to create the 3D model is provided by many software products.

Based on the 3D model of the object, the creation of a simulator based on virtual reality technology (VR simulator) is proposed [1]. It is used for conducting operational switching operations in normal regime, emergency response training, teaching, certification and conducting professional skill competitions among the operating personnel of the power supply department. It is proposed that an individual simulator be created for each power facility (substation of a power system, kiosk substation, distribution point, transformer substation) according to its scheme. The simulator represents a model of the power facility as close as possible to the actual conditions. Such a solution allows not only conducting training exercises, but also to improve the quality of training of operational personnel and may have a positive impact on the stability of the enterprise, reduce the risk of emergency regimes and accidents. It is also proposed to perform the design of linear-type objects of the power supply system with reference to the geographical coordinates on the ground. Nowadays, there are programs in the domestic software market that have this functionality.

The connection of the computational model, presented in the form of a single-line diagram of the electrical power network, with geographic data allows:

a) design engineers 
- to construct an electrical power network diagram with drawing an electrical installations on the terrain map;

- to obtain the correct lengths of network linear-type objects and, as a result, the correct parameters of their equivalent circuits;

- to take into account the features of the location of objects on the ground when forming a single-line diagram of the electrical power network and planning the development of the territory;

- to form the plans for the location of electric lines associated with the single-line diagram of the electrical power network for the release of project documentation;

- b) maintenance service

- to receive from the model the names of electrical power network units, support numbers for operational and repair work;

- to keep the model up to date during the operation taking into account the modernization and development of network complexes.

- To issue the project and detailed documentation (drawings, computational models, equipment specifications, questionnaires) it is necessary to use specialized programs that allow engineers to perform:

- electric power supply circuits and principle circuits of electrical switchboards designed in accordance with Russian National Standards;

- calculations of electrical loads, short circuit currents, voltage drops, striking short circuit currents, power losses, etc.;

- cable logs and cable specifications.

The connection of the calculated software modules and the 3D model allows importing cable lengths from the 3D model for automated cable log generation, cable routing flows, cable connection tables, specifications. Moreover, such approach allows automated filling trays and racks on cable routes, allows preparing a job for calculating the structural part of the supporting structures. Albums of typical solutions, produced in addition to the main project and available to the construction contractor, can reduce the degree of detail of the drawings and reduce the labor costs for the production of documentation. The albums may contribute to the unification of the decisions made, improve the quality of installation work and minimize the downtime during installation.

A separate section of the digital model of the project includes the logistics of equipment and materials and combines project, competitive and procurement documentation. This section makes it possible to track the movement of nomenclature units in the bases, warehouses, places of final assembly.

The specification of equipment, products and materials is the main document. In this specification, the initial assignment of a unique number from the classifier for each ordered piece of equipment occurs. This number is used to track equipment at the stage of tender procurement, submission of a technical and commercial proposal from a potential supplier. Reviewing of detailed documentation, supply chain monitoring, transferring from the warehouse to the installation, submitting the installation certificate, signing of author's supervision - all of these stages are required this unique number. Having the initial information, there is a possibility of automated filling of the template of the installation certificate for the contracting construction organization and other related documents (invoices, forms, cards, etc.).

When receiving data from the manufacturer, the database is updated with the passport data of the equipment that will be used by the maintenance service and displayed in the calculated single-line diagram and the virtual simulator database. For example, for a power transformer, these parameters are:

- operating parameters (rated power, rated winding currents, rated winding voltage, blank work losses, voltage ratio factor, active and reactive resistances); 
- number of primary windings;

- transformer windings group;

- on-load tap changing ability

The cyclical relationship between the various sections of project makes it possible all interested units of the enterprise to have relevant and consistent information. As a rule, the logs of design supervision do not come back from the construction site back to the department of engineering or come as separate change requests. There is no complete information about all the changes that the detailed documentation has undergone during the construction of the object.

Implementation of the logs of design supervision into the united digital model of the project allows you:

- to form a complete picture of the object;

- to analyze the previous mistakes when designing the following similar objects;

- to create a scheme corresponding to the operating scheme taking into account all changes made to its configuration (additional power consumers its number and rated power);

- to have information about the replacement of equipment and cable products during construction.

The contractor may execute as-built documentation based on drawings and specifications of detailed documentation contained in an editable form in the data warehouse. This reduces the time for its preparation. If there are agreed deviations from the detailed documentation, a link is automatically generated to the entry in the log of design supervision (Fig. 2). This ensures the correctness and transparency of the construction and installation works being carried out.

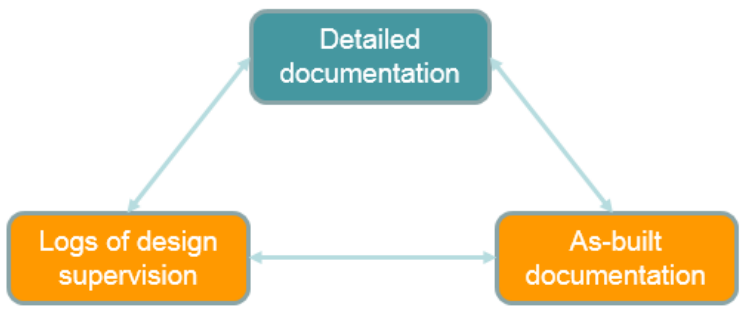

Fig. 2. The structural scheme of interactions in the process of making changes to the documentation.

The detailed documentation, data on the actually mounted equipment and its characteristics will be the basis for creating a mathematical algorithm. The algorithm will allow estimating the residual service life of the equipment before the scheduled decommissioning for maintenance and repair.

For example, for turbines at a power plant, according to the design loads, it is possible to analyze their current load, operating time, modes, plan the next maintenance and understand the electricity generation needs.

Practically more than $50 \%$ of failures of production equipment could be prevented by applying predictive diagnostics [2]. Moreover, $15-25 \%$ of these failures are connected to equipment without duplication and termination of the production process during the liquidation of the accident entails direct losses.

For example, in relation to oil pumping stations, the use of predictive diagnostics of process equipment allows collecting and systematizing information on the current operating parameters of a group of pumping units, on the actual loads of their electric motors. The diagnostics allows assessing the state of the frequency converters' power cells, analyzing the level of electromagnetic interference and vibrations. Information obtained during 
predictive diagnostics can become the basis for the development of methods for energyefficient control of pumping stations electric drives.

For planning equipment rounds and inspections, it is possible to use an automated way of filling the permit to work and automated filling of a report on a pre-set template, based on the design data on the equipment and the place of its installation. The name, passport data, inventory number are entered into the form automatically [3-6].

\section{Conclusions}

1. Creating a single information field to store all the information about the objects being designed, as well as about the objects that have already been put into operation, allows you to get quick access to the information, which allows you to use working time more efficiently.

2. In a single information space, it will always be possible to compare the passport data of the equipment with the actual ones, assess the quality of the equipment of a particular manufacturer, and draw conclusions about its further applicability at similar objects.

3. Information obtained during predictive diagnostics can become the basis for the development of new energy-efficient methods of the control of various technological equipment.

\section{References}

1. W. Zhi-qiang, Procedia Engineering 174, 1336-1339 (2017) doi: 10.1016/j.proeng.2017.01.284

2. A. Kumar, R. Shankar, L. Thakur, Journal of Computational Science 27, 428-439 (2018) doi: 10.1016/j.jocs.2017.06.006

3. S. Rinaldi, A Flammini, M. Pasetti, L. C. Tagliabue, A. C. Ciribini, S. Zanoni, Metrological Issues in the Integration of Heterogeneous IoT Devices for Energy Efficiency in Cognitive Buildings, 2018 IEEE International Instrumentation and Measurement Technology Conference (I2MTC), 14-17 May 2018, Houston, Texas, USA (2018). DOI: 10.1109/I2MTC.2018.8409740

4. S. Rinaldi, M. Pasetti, E. Sisinni, F. Bonafini, P. Ferrari, M. Rizzi, A. Flammini, On the Mobile Communication Requirements for the Demand-Side Management of Electric Vehicles. Energies, 11, 51220 (2018), DOI: 10.3390/en11051220

5. B. Marchi, S. Zanoni, M. Pasetti, Industrial Symbiosis for Greener Horticulture Practices: The $\mathrm{CO} 2$ Enrichment from Energy Intensive Industrial Processes, Proc CIRP, 25th CIRP Life Cycle Engineering (LCE) Conference, 30 April - 2 May 2018, Copenhagen, Denmark 562-567, 69 (2018), DOI: 10.1016/j.procir.2017.11.117

6. I.V. Ilin, A. Lepekhin, A.I. Levina, O.Yu. Iliashenko, Advances in Intelligent Systems and Computing, 692, 1306-1314 (2018) DOi -10.1007/978-3-319-70987-1_138 